\title{
The prevalence of Stevens Johnson Syndrome caused by antiretroviral in hospitalized patients at Dr. Hasan Sadikin General Hospital Bandung
}

\author{
Nurmilah Maelani*, Irna Sufiawati*, Hartati Purbo Darmadji** \\ *Department of Oral medicine Faculty of Dentistry Universitas Padjadjaran \\ **Department of Skin and Genital Faculty of Medicine Universitas Padjadjaran
}

\section{ABSTRACT}

Stevens Johnson Syndrome is a mucocutaneous disease caused by allergic drug eruption. Antiretroviral (ARV) therapy for HIV/AIDS patient may cause allergic drug eruption such as Stevens Johnson Syndrome. The aim of this research was to find out the prevalence of Stevens Johnson Syndrome caused by ARV in hospitalize patient at Dr. Hasan Sadikin General Hospital Bandung from January to December 2008. It was a descriptive research by taking the secondary data from patient's medical record. The result of this research showed that from 20 Stevens Johnson Syndrome patients, 12 persons of them $(60 \%)$ are men. Most of the patients were between the age of 20-29 (45\%). Oral manifestation of Stevens Johnson Syndrome seen in $100 \%$ patients. Prevalence of Stevens Johnson Syndrome caused by ARV was $28.6 \%$ which seen in 8 HIV/AIDS patients. ARV combination consist of nevirapine, lamivudine, and zidovudine was the most (50.0\%) ARV which suspected causing Stevens Johnson Syndrome. The conclusion of this research showed that the prevalence of Stevens Johnson Syndrome caused by ARV in hospitalize patient at Dr. Hasan Sadikin General Hospital Bandung 2008 was $28.6 \%$ seen in 8 HIV/AIDS patients.

Key words: Antiretroviral, Sindrom Stevens Johnson

\section{INTRODUCTION}

Stevens Johnson Syndrome (SJS) is a hypersensitivity reaction of immune complex at mococutaneous mostly caused by medications and infections. Stevens-Johnson Syndrome symptoms are the spread of macular skin eruption, with a typical target lesion (flat, irregular) and involve more than one of mucosa (oral cavity, conjunctivitis and genital). ${ }^{1,2}$

Antiretroviral (ARV) is one of the medications caused SJS which were given for Human Immunodeficiency Virus (HIV)/Acquired Immunodefi- ciency Syndrome (AIDS) infection therapy. ${ }^{3}$ Ananworanich et al. in their research stated that nevirapine made two of HIV infected patients suffered from Stevens-Johnson Syndrome. ${ }^{4}$ Nevirapine is a non-nucleoside reverse transcriptase inhibitor, used in combination with others antiretroviral medications for the treatments of HIV infection.

Mococutaneous disorder such as StevensJohnson Syndrome firstly occurred in oral. The early anticipation gave much help to prevent the further spread of skin eruption. ${ }^{6}$ Dentists played the vital roles in identifying patients with druginduced oral ulcers and facilitating patients for 
their medications and treatments. ${ }^{7}$

This research was aimed to get information about the prevalence of Stevens Johnson Syndrome caused by antiretroviral medications in hospitalized patients at Dr. Hasan Sadikin General Hospital, Bandung, during the period of JanuaryDecember 2008.

\section{MATERIALS AND METHODS}

The research sources were all the medical records in Dr. Hasan Sadikin General Hospital's Medical Records of hospitalized patients morbidity which coded ICD L51.1 and L51.2 code from $1^{\text {st }}$ of January to $31^{\text {st }}$ of December, 2008. In which, the ICD L51.1 is a legal code from WHO to diagnose bullous, and ICD L51.2 code is also a legal WHO's code to diagnose Toxic Epidermal Necrolysis.

The research desymptom was retrospectively descriptive research, which described the prevalence of Stevens Johnson Syndrome caused by antiretroviral medications at Dr. Hasan Sadikin General Hospital, Bandung during January-December 2008 periods. The research was conducted based on the secondary data, i.e. patients' medical records which suitable with the research vari-

Table 1. The distribution of patients diagnosed as Bulbous and Toxic Epidermal Necrolysis based on sex and age

\begin{tabular}{|c|c|c|c|c|}
\hline \multirow{2}{*}{$\begin{array}{c}\text { Age } \\
\text { (year) }\end{array}$} & \multicolumn{2}{|c|}{ Sex } & \multirow{2}{*}{ Total } & \multirow{2}{*}{ (\%) } \\
\hline & $L$ & $\mathbf{P}$ & & \\
\hline $0-9$ & 2 & 4 & 6 & 15,8 \\
\hline $10-19$ & 2 & 6 & 8 & 21,1 \\
\hline $20-29$ & 9 & 3 & 12 & 31,6 \\
\hline $30-39$ & 5 & 0 & 5 & 13,1 \\
\hline $40-49$ & 1 & 1 & 2 & 5,3 \\
\hline $50-59$ & 1 & 0 & 1 & 2,6 \\
\hline$>60$ & 2 & 2 & 4 & 10,5 \\
\hline Total & 22 & 16 & 38 & 100,0 \\
\hline
\end{tabular}

ables. In addition, this research variables are Steven-Johnson Syndrome and antiretroviral.

\section{RESULTS}

According to the research, 38 patients, diagnosed as suffered from Bollous and Toxic Epidermal Necrolysis, were found from medical records of hospitalized patients' morbidity at Dr. Hasan Sadikin General Hospital Bandung in 2008.

The below table showed the prevalence of Stevens Johnsons Syndrome based on patients' age, ranged from 20-29 years old were 12 persons ( 31 . $6 \%$ ) regarded as the biggest amount of patients, and the lowest one was only person $(2.6 \%)$ at the age of 50-59 years old.

The distribution of data based on Bullous and Toxic Epidermal Necrolysis found that the numbers of patients which were diagnosed of SJJ were 20 persons $(52.6 \%)$ (Fig. 1), furthermore, it also found that 8 people $(21.1 \%)$ diagnosed as suffering from SJJ and TEN. Table 3 above described that all of Steven Johnsons Syndrome

Table 3. Distribution of Steven Johnson Syndrome based on predilections

\begin{tabular}{lcc}
\hline Location of lesion & Total & $\%$ \\
\hline Eye & 20 & 100,0 \\
Skin & 20 & 100,0 \\
Genital & 7 & 35,0 \\
Oral & 20 & 100,0 \\
\hline
\end{tabular}

Table 4. Distribution of Steven Johnson Syndrome overlap with toxic epidermal necrolysis based on predilections

\begin{tabular}{lcc}
\hline Location & Total & $\%$ \\
\hline Eye & 8 & 100 \\
Skin & 8 & 100 \\
Genital & 4 & 50 \\
Oral & 8 & 100 \\
\hline
\end{tabular}

Table 2. Cross-tabulation data on the distribution of Bulbous and Toxic Epidermal Necrolysis diagnosis based on sex

\begin{tabular}{lcccccc}
\hline \multirow{2}{*}{ Diagnosis } & \multicolumn{3}{c}{ Sex } & \multicolumn{3}{c}{ Total } \\
\cline { 2 - 7 } & $\mathrm{L}$ & $\%$ & $\mathrm{P}$ & $\%$ & Total & $\%$ \\
\hline SJS & 12 & 31,6 & 8 & 21,1 & 20 & 52,6 \\
SJS + TEN & 5 & 13,1 & 3 & 7,9 & 8 & 21,1 \\
TEN & 2 & 5,3 & 4 & 10,5 & 6 & 15,8 \\
Fixed drug eruption & 3 & $\mathbf{7 , 9}$ & 1 & 2,6 & 4 & 10,5 \\
\hline Total & $\mathbf{2 2}$ & $\mathbf{5 7 , 9}$ & $\mathbf{1 6}$ & $\mathbf{4 2 , 1}$ & $\mathbf{3 8}$ & $\mathbf{1 0 0 , 0}$ \\
\hline
\end{tabular}




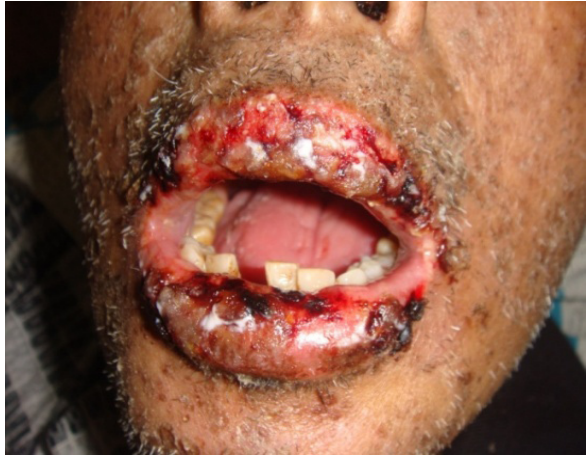

Figure 1. Manifestation of SJS e.c. Neviral suspect on oral of 52 years old man patient.

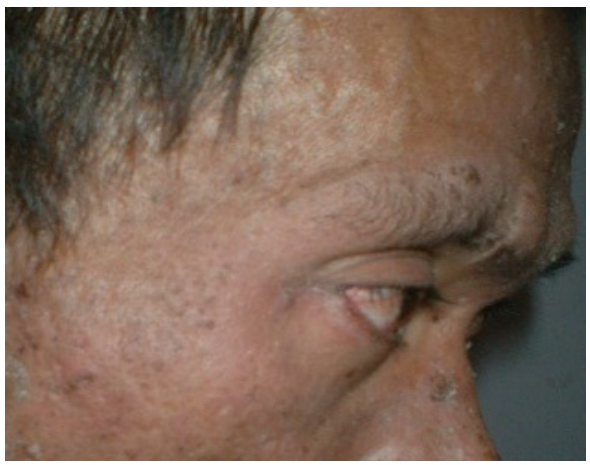

Figure 2. Manifestation of SJS e.c Efavirenz suspect on eyes of 36 years old man patient.

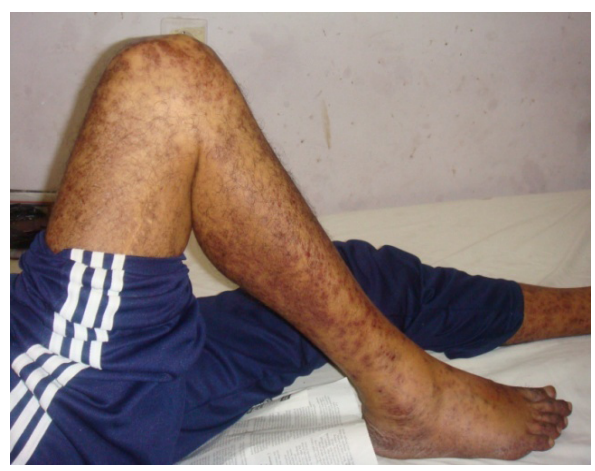

Figure 3. Manifestation of SJS e.c. Neviral suspect on skin, The patient is $\mathbf{5 2}$ years old man.

patients $(100 \%)$ had clinical symptoms on oral, eyes and skin. Meanwhile, the clinical symptoms on genital only occurred in 35\% the patients. Table 4 showed that all the patients of Steven Johnson Syndrome overlap Epidermal Necrolysis have clinical symptoms on oral, eyes and skin, and only $50 \%$ on genital. Table 5 showed that the prevalence of Steven Johnson Syndrome Patients caused by ARV reached $28.6 \%$. Based on the above table, Steven Johnson Syndrome found frequently in patients, who was treated by Neviral and Duviral
Table 5. The patients' percentage of SSJ and SSJ syndrome overlap toxic epidermal necrolysis based on medications etiology

\begin{tabular}{lcc}
\hline Drug as a etiologic suspect & Total & (\%) \\
\hline ARV & 8 & 28.6 \\
Non ARV & 20 & 71.4 \\
\hline Total & 28 & 100.0 \\
\hline
\end{tabular}

Table 6. The kinds of ARV predicted as the caused of Steven Johnson Syndrome in HIV patients

\begin{tabular}{lcc}
\hline Type of drug & Total & (\%) \\
\hline Efavirenz & 1 & 12.5 \\
Nevirapine & 1 & 12.5 \\
Nevirapine + Lamivudin + Stavudin & 2 & 25.0 \\
Neviral (Nevirapine) + & & \\
Duviral (Lamivudin + Zidovudin) & 4 & 50.0 \\
\hline Total & $\mathbf{8}$ & $\mathbf{1 0 0 . 0}$ \\
\hline
\end{tabular}

combination therapy, i.e. 4 persons (50.0\%).

\section{DISCUSSION}

During the research, there are 38 patients from hospitalized patients' morbidity data at Dr. Hasan Sadikin Bandung in 2008. There were 20 patients (52.6\%) diagnosed as suffered from Steven Johnson Syndrome, and 8 persons or $21.1 \%$ were suffered from SJS + TEN. The result of the research indicated the bigger prevalence, if compared with others researches. On the Noel, et al.'s research, out of 56 patients, $15 \%$ of them suffered from SJS and 35\% suffered from maculopapular skin eruption. ${ }^{8}$ Others researches found that the SJS incident in Spain is approximately 1-2 cases per a million population. ${ }^{9}$

The literature described that based on sex, the comparative amount of SJS patients, men to women were $2: 1 .^{10}$ The literature's research showed the same outcome, means more men suffered from SJS predilection than women did. Approved by Table 2, SJS were diagnosed in 2008 at RSHS by the amount of 12 men (31.6\%) which were more than women patients; $8(21.1 \%){ }^{10}$

From 20 SJS patients, prevalence was mostly occurred between the ages of 20-29 years old, i.e. 9 persons (45\%). SJS incident based on age criterion in this research, had almost the same result with former researches all over the 
world. According to Parillo et al. ${ }^{10}$ in Philadelphia, the SJS patients were between the ages of 20-40 years old, even though there was an SJS report on 3 month-old baby. Noel et al. ${ }^{8}$ also offered the equivalent result that the SJS patients' in India was mostly between the ages of 21-40 years old.

The research on prevalence of antiretroviral medications as the caused of SJS resulted in $28.6 \%$. The type of antiretroviral that had the biggest prevalence is the combination of Nevirapine, Lamivudine and Zidovudine, which found at four persons (50\%). Meechan and Seymour said that Nevirapine (NVP) and Efavirenz (EFV) were the caused of Stevens Johnson Syndrome; moreover, Zidovudine can caused the swell of the lips and tongues. ${ }^{11}$ It was reported to the US Food and Drug Administration that there were 19 cases of SJS and TEN caused by Nevirapine since the approvement of nevirapine used, on June 1996. The biggest risk of mucocutaneous reaction at Nevirapine therapy on HIV infected patients became the most occurred cases than other medication. ${ }^{12}$ Fagot et al. ${ }^{13}$ found that from 18 patients infected by HIV, 15 of them were diagnosed as SJS patients caused by Nevirapine. The researchers from Uganda report two cases of SJS in a mother and an 8 years old son, in which both of them were used Nevirapine combined with Stavudine and Lamivudine. ${ }^{2}$

The major toxicity of the first-line antiretroviral in the combinations of Zidovudine, Lamivudine and Nevirapine, and the combinations of Stavudine, Lamivudine, and Nevirapine was the heavy skin eruption because of Nevirapine. If it was not a life threatening condition, with clinical symptoms of no pustule, and didn't reach mucosa, then Nevirapine therapy can be substituted with Efavirenz. Meanwhile, if there was a heavy skin eruption, which was threaten the life (Stevens Johnson Syndrome) because of Nevirapine therapy, then the medications can be substituted by protease inhibitor. ${ }^{4}$

A patient with a heavy skin eruption from Nevirapine should be discontinued the medication and should not be substituted by Efavirenz. The used of Efavirenz in substituting Nevirapine at the patient with smaller skin eruption, remained risked the patient for suffering the same skin eruption. In the case of ARV failed in the first-line which contained NNRTI (Nevirapine or Efavirenz), the switch of both medications was not suggested because of the high resistance across NNRTI. Viruses at the patients, which failed on therapy of Efavirenz, proved to be résistance to Efavirenz and Nevirapine. Some others observational studies also showed the unresponded therapy to Efavirenz after the failing nevirapine. ${ }^{4}$

The second-line antiretroviral for HIV/ AIDS infected adult, in the case of failed therapy at first line regime or in other words the failed on Stavudine or Zidovudine or Lamivudine and Nevirapine or Efavirenz therapies, they can be replaced by Tenofovir Disoproxil Fumarate (TDF) or Abacavir, Didanosine and Lopinavir or Saquinavir. To substitute medications from non-nucleoside reverse transcriptase inhibitor (NNRTI) group depended on the reason of the discontinuity, for example in hard or fatal toxicity case, then all the usage of these medications should be stopped immediately.

\section{CONCLUSION}

The prevalence of Stevens Johnson syndrome caused by antiretroviral in hospitalized patients at Dr. Hasan Sadikin Bandung in 2008 was $28.6 \%$. The antiretroviral that suspected to be the caused of Stevens Johnson Syndrome was the combinations of Nevirapine, Lamivudine and Zidovudine. Dentists have major roles on the treatment of Steven Johnson Syndrome patients and consequently they had to have enough knowledge on disorder oral mucosa caused of medications side-effects.

\section{REFERENCES}

1. Fitzpatrick TB. Fitzpatrick's dermatology in general medicine. $5^{\text {th }}$ ed. London: The McGraw-Hill; 1999. Vol 1. p. 59.

2. Namayanja GK. Stevens Johnson Syndrome due to nevirapine. Uganda: Makarere Medical School. 2005.

3. Department of Health and Human Services. Guidelines for the use of antiretroviral agents in HIV-1-infected adults and adolescents. 2008. [cited 2009 Jun 10] Available from:http: www.aidsinfo.nih.gov/Content Files?Adultand AdolescentGL.pdf.

4. Ananworanich J. Incidence and risk factors for rash in Thai patients randomized to regimens with Nevirapine, Efavirenz or both drugs. 
Epidemiology and Social AIDS 2005;19(2):18592.

5. Depkes RI. Pedoman nasional terapi antiretroviral. 2004 [cited 2009 Jun 10]. Available from: http://www.i-base.info/ itpc/Indonesian/spirita/docs/pedoman-ART04.pdf.

6. Lewis MAO. Tinjauan klinis penyakit mulut. Jakarta: Penerbit Buku Kedokteran Widya Medika; 1998.

7. Cohen DM. Recalcitrant oral ulcers caused by calsium channel blockers: Diagnosis and treatment considerations. JADA 1999;130.

8. Noel M, Sushma V, Giudo S. Cutaneous adverse drug reactions in hospitalized patients in a tertiary care center. J Pharmacol Indian 2004;36(5):292-5.

9. Villar. Case report: positive patch test with phenytoin in a case of Stevens Johnson Syndrome. JAlergol Immunol Clin 2001;16:1746.

10. Parillo. Stevens Johnson Syndrome. 2005 [cited 2009 Jun 10]. Available from:http:// www.eMedicine.com.

11. Meechan JG, Seymour RA. Drug dictionary for dentistry. New York: Oxford University Press Inc.; 2002.

12. Warren KJ. Nevirapine-associated Stevens Johnson Syndrome. The Lancet Vol. 351. Maryland: United States Food and Drug Administration. 1998 [cited 10 Jun 2009]. Available from:http//www.altheal.org/pdf/ nevirapine2.pdf.

13. Fagot. Nevirapine and the risk of SevensJohnson Syndrome or Toxic Epidermal Necrolysis. AIDS 2001;15(14):1843-8. 